\title{
PEMBINAAN BAHASA INDONESIA YANG BAIK DAN BENAR DIKALANGAN MAHASISWA DI ERA MILENIAL MELALUI MEDIA SOSIAL
}

\author{
Nana Triana Winata \\ Universitas Wiralodra, Prodi Pendidikan Bahasa dan Sastra Indonesia, \\ nanawinata26@gmail.com
}

\begin{abstract}
Indonesian is the national language of the Indonesian state which has rules in accordance with PUEBI. In communicating, both verbally and in writing, we use language skills that we already have, even though everyone has different levels or qualities. People who have optimal language skills, every communication goal will be easily achieved. It's different for people who have a weak level of language skill, in communicating it's not the goal that will be achived, but instead misunderstandings will often arise between the speaker and the interlocutor. The purpose of this study is to form a good and correct understanding of the use of Indonesian in the digital era among students, as well as equip the target audience to behave positively on social media, so as to form overt behavior that is visible from the target audience. This study uses a qualitative descriptive method, meaning that the researcher analyzes the data collected in the form of words, pictures and not numbers. From the results of the coaching carried out through social media Instagram and Tik Tok, there was a positive response from the Indonesian language coaching participants. They get a lot of new knowledge from the uploads. The result of upload both via Instagram and Tik Tok can be a provision for all groups in using good and correct Indonesian in accordance with the applicable PUEBI
\end{abstract}

Keyword(s): Indonesian Language Development, Good and Right Language, Social Media Language

\begin{abstract}
ABSTRAK
Bahasa Indonesia adalah bahasa nasional negara Indonesia yang memiliki kaidah-kaidah sesuai dengan PUEBI. Dalam berkomunikasi, baik lisan maupun tulisan, kita menggunakan keterampilan berbahasa yang telah dimiliki, meskipun setiap orang memiliki tingkatan atau kualitas yang berbeda-beda. Orang yang memiliki keterampilan berbahasa secara optimal, setiap tujuan komunikasinya akan dapat dengan mudah tercapai. Lain halnya bagi orang yang memiliki tingkat keterampilan bahasa lemah, dalam melakukan komunikasi bukan tujuannya yang akan tercapai, tetapi justru akan sering timbul kesalahpahaman antara penutur dan mitra tuturnya. Tujuan dalam penelitian ini adalah membentuk pemahaman penggunaan bahasa Indonesia yang baik dan benar di era digital pada kalangan mahasiswa, serta membekali target khalayak dalam berperilaku positif di media sosial, sehingga terbentuk perilaku terbuka (overt behavior) yang tampak dari target khalayak. Penelitian ini menggunakan metode deskriptif kualitatif, berarti peneliti menganalisis data yang dikumpulkan dapat berupa kata-kata, gambar dan bukan angka-angka. Dari hasil pembinaan yang dilakukan melalui media sosial instagram dan tik tok, mendapatkan respons positif dari peserta pembinaan bahasa Indonesia. Banyak pengetahuan baru yang mereka dapatkan dari hasil unggahan. Hasil unggahan baik itu melalui instagram dan tik tok dapat menjadi bekal untuk semua kalangan dalam menggunakan bahasa Indonesia yang baik dan benar sesuai dengan PUEBI yang berlaku.
\end{abstract}

Kata Kunci : Pembinaan Bahasa Indonesia, Bahasa Baik dan Benar, Bahasa Media Sosial 
How to Cite: Winata, N. T. (2021). PEMBINAAN BAHASA INDONESIA YANG BAIK DAN BENAR DIKALANGAN MAHASISWA DI ERA MILENIAL MELALUI MEDIA SOSIAL. Bahtera Indonesia; Jurnal Penelitian Bahasa Dan Sastra Indonesia , 6(2), 267-275. https://doi.org/10.31943/bi.v6i2.141

DOI: https://doi.org/10.31943/bi.v6i2.141

\section{PENDAHULUAN}

Keterampilan berbahasa tidak hanya didapatkan dalam pembelajaran di sekolah. Keterampilan berbahasa dimulai dari bahasa pertama yaitu bahasa ibu yang kemudian akan diolah pada jenjang pendidikan dimulai dari Sekolah Dasar (SD), Sekolah Menengah Pertama (SMP), Sekolah Menengah Atas (SMA), hingga perguruan tinggi.

Salah satu bentuk komunikasi secara lisan adalah keterampilan berbicara. Pada keterampilan berbicara ini, kita melakukan komunikasi secara dua arah. Tujuannya adalah untuk menyampaikan informasi atau gagasan kepada lawan tutur. Pada penyampaiakan informasi tersebut menggunakan bahasa "asal orang mengerti" tanpa memperhatikan kaidah kebahasaan yang digunakan.

Menurut Soulisa (2018) pengajaran keterampilan berbicara mencakup kenyaringan suara, kelancaran, sikap berbicara, gerak-gerik mimik muka, penalaran, santun berbicara. Keterampilan berbicara mahasiswa kurang memperhatikan kaidah kebahasaan yang ada menurut ketentuan yang berlaku seperti PUEBI
(Pedoman Umum Ejaan Bahasa Indonesia) dan KBBI (Kamus Besar Bahasa Indonesia).

Seseorang yang memiliki kemampuan berbicara akan lebih mudah menyampaikan ide atau gagasan kepada orang lain, sehingga dapat diterima oleh orang yang mendengar atau diajak berbicara (Laelasari, dkk, 2018). Jika mahasiswa tidak memiliki kemampuan dalam berbicara, mahasiswa tersebut tidak akan bisa menyampaikan ide atau gagasan kepada forum diskusi. Butuh pelatihan atau kebiasaan agar keterampilan berbicara mahasiswa sesuai dengan kaidah kebahasaan atau mahasiswa tersebut dapat menggunakan bahasa Indonesia yang baik dan benar. Bahasa yang baik menurut tatakrama yang ada di Indonesia dan bahasa yang benar menurut kaidah kebahasaan PUEBI dan KBBI.

Menurut Sahril (2016) Banyak orang yang mengeluh dan merasa kesulitan belajar bahasa asing tetapi mereka lupa bahwa kesulitan itu sebenarnya disebabkan oleh penguasaan bahasa Indonesia yang masih belum memadai. Hal tersebut menjadi faktor yang dilupakan penutur bahasa Indonesia yang terlalu mengesampingkan bahasa Indonesia menjadi bahasa utama dalam 
berkomunikasi. Badan Pengembangan dan Pembinaan Bahasa, Kementerian Pendidikan, Kebudayaan, Riset, dan Teknologi membuat selogan yang berbunyi "Utamakan Bahasa Indonesia, Lestarikan Bahasa Daerah, dan Kuasai Bahasa Asing", sudah sangat jelas dalam berkomunikasi baik secara lisan atau tulis harus mengutamakan menggunakan bahasa Indonesia.

Sebetulnya pembelajaran Bahasa Indonesia ada pada setiap jenjang pendidikan baik itu tingkat SD, SMP, SMA, hingga perguruan tinggi. Pada praktinya penggunaan bahasa Indonesia secara lisan masih banyak mahasiswa yang belum menggunakan bahasa Indonesia yang baik dan benar.

Bahasa Indonesia adalah bahasa nasional negara Indonesia yang memiliki kaidah-kaidah sesuai dengan PUEBI. Dalam berkomunikasi, baik lisan maupun tulisan, kita menggunakan keterampilan berbahasa yang telah dimiliki, meskipun setiap orang memiliki tingkatan atau kualitas yang berbeda-beda. Orang yang memiliki keterampilan berbahasa secara optimal, setiap tujuan komunikasinya akan dapat dengan mudah tercapai. Lain halnya bagi orang yang memiliki tingkat keterampilan bahasa lemah, dalam melakukan komunikasi bukan tujuannya yang akan tercapai, tetapi justru akan sering timbul kesalahpahaman antara penutur dan mitra tuturnya.
Salah satu hambatan dalam proses komunikasi adalah kurangnya keterampilan berbahasa. Wujud dari kurangnya keterampilan berbahasa itu antara lain disebabkan oleh kesalahan kesalahan berbahasa. Kesalahan kesalahan berbahasa ini menyebabkan gangguan terhadap peristiwa komunikasi, kecuali dalam hal pemakaian bahasa secara khusus seperti dalam lawak, jenis iklan tertentu, serta dalam puisi. Dalam pemakaian bahasa secara khusus itu, kadangkadang kesalahan berbahasa sengaja dibuat atau disadari oleh penutur untuk mencapai efek tertentu sepeti lucu, menarik perhatian dan mendorong berpikir lebih intens.

Perkembangan teknologi memengaruhi penutur bahasa dalam menggunakan bahasa Indonesia, baik dilingkungan sekolah, kerja, sosial, bahkan hingga penggunaan bahasa pada media sosial. Perkembangan teknologi komunikasi yang terjadi selama era peradaban manusia turut memengaruhi aspek-aspek kehidupan masyarakat di berbagai bidang, mulai dari ideologi, ekonomi, politik, sosial, budaya, pertahanan, dan keamanan. Mulai dari kemunculan buku sebagai teknologi komunikasi dengan kategori media massa cetak, surat kabar, majalah, radio, televisi, rekaman musik, film, video games, hingga kemunculan teknologi internet yang menjadi gerbang terciptanya berbagai teknologi media massa modern, seperti media sosial yang telah 
menjadi bagian yang tidak terpisahkan dalam kehidupan masyarakat di era digital.

Adapun tujuan umum yang ingin dicapai dari penelitian ini adalah membentuk pemahaman penggunaan bahasa Indonesia yang baik dan benar di era digital pada kalangan mahasiswa, serta membekali target khalayak dalam berperilaku positif di media sosial, sehingga terbentuk perilaku terbuka (overt behavior) yang tampak dari target khalayak.

\section{METODE PENELITIAN}

Penulis menggunakan metode penelitian deskriptif kualitatif, Menurut Moleong (2010) dengan menggunakan metode deskriptif berarti peneliti menganalisis data yang dikumpulkan dapat berupa kata-kata, gambar dan bukan angkaangka. Data tersebut mungkin berasal dari naskah wawancara, catatan lapangan, foto, video tape, dokumen pribadi, catatan atau memo dan dokumen resmi lainnya. Pengambilan sampel secara acak tanpa memperhatikan strata yang ada dalam populasi (Sugiyono, 2016). Pada penelitian ini membentuk pemahaman mahasiswa terhadap penggunaan bahasa Indonesia melalui media sosial.

\section{HASIL DAN PEMBAHASAN}

Bahasa merupakan media yang digunakan anggota suatu kelompok sosial untuk berkomunikasi, berinteraksi, dan sebagai identitas diri. Bahasa dapat menggiring kita menembus ruang dan waktu. Melalui bahasa, kita dapat mempelajari ilmu pengetahuan, sejarah, maupun adat istiadat suatu bangsa dalam masa tertentu. Bahasa mampu merekam berbagai hal tersebut dalam bentuk lisan maupun tulisan. Semua itu merupakan fungsi bahasa yang telah lama diemban oleh bahasa Indonesia.

Bahasa Indonesia adalah bahasa nasional Negara Indonesia yang merupakan bahasa pemersatu. Bahasa Indonesia sudah diajarkan sejak tingkat SD, SMP, dan SMA. Oleh karena itu, sebaiknya setelah jenjang SMA bahasa Indonesia sudah dikuasai atau setidaknya mempunyai pengetahuan yang memadai tentang Bahasa Indonesia. Namun faktanya, masih sedikit mahasiswa yang memiliki kemampuan berbahasa Indonesia secara maksimal.

Untuk memelihara, melindungi, dan mewujudkan bahasa Indonesia agar tetap dicintai dan digunakan oleh bangsa Indonesia, Pemerintah Republik Indonesia melalui Undang-Undang sistem pendidikan Nasional (Sisdiknas) menetapkan bahasa Indonesia 
sebagai pengantar dalam setiap tingkatan pendidikan nasional. Hal itu tercantum dalam UU RI Nomor 20 tahun 2003 tentang Sisdiknas, BAB VII, Pasal 33 ayat 1 yang berbunyi ${ }^{\text {eee }}$ Bahasa Indonesia sebagai bahasa negara menjadi bahasa pengantar dalam pendidikan nasionale ${ }^{\text {ee }}$ Sebagai implementasi dari UU Sisdiknas tersebut, pemerintah menetapkan kurikulum nasional dan garisgaris besar prorgram Pengajaran Bahasa Indonesia untuk setiap tingkatan sekolah yang ada di Indonesia.

\section{Pembinaan Bahasa Indonesia secara}

\section{Daring}

Pada masa pandemi Covid-19 ini, pembinaan bahasa Indonesia kepada mahasiswa dilakukan secara daring menggunakan media zoom meeting. Dalam kegiatan pembinaan bahasa Indonesia melalui media zoom meeting pada mahasiswa ini, mahasiswa dibekali materi tentang ejaan. Sejarah ejaan yang pernah digunakan di Indonesia. Ejaan itu sendiri adalah ketentuan yang mengatur perlambangan bunyi bahasa termasuk pemisahan dan penggabungan huruf atau kata sebagai lambang bahasa itu sendiri dan dilengkapi dengan penggunaan tanda baca. Mulai dari Ejaan Van Ophuijsen yang belum banyak diketahui oleh peserta zoom meeting ini, sejarah dari Ejaan Van Ophuijsen itu sendiri Charles Adriaan van Ophuijsen berasal dari Belanda yang gemar mempelajari bahasa berbagai suku di Hindia-Belanda, dia merupakan Kepala Sekolah pertama SMAN 2 Bukittinggi (1900). Van Ophuijsen mendapat perintah untuk merancangkan ejaan bahasa Melayu dengan huruf latin guna pengajaran.

$$
\text { Van Ophuisjen bersama dengan }
$$
Engku Nawawi yang bergelar Soetan Ma'moer dan Muhammad Taib Sutan Ibrahim, menyusun ejaan baru untuk mengganti ejaan bahasa Melayu di tahun 1896. pedoman tata bahasa yang kemudian dikenal dengan nama Ejaan Van Ophuijsen resmi diakui pemerintah kolonial pada tahun 1901. Beliau pada akhirnya diangkat menjadi guru besar ilmu bahasa dan kesusastraan Melayu di Leden University (1904).

Beberapa hal yang menonjol dalam Ejaan Van Ophuijsen ini sangat mencolok sekali, ketika kita bandingkan dengan ejaan yang saat ini digunakan dikalangan siswa atau mahasiswa yang ada di Indonesia. Hal yang mencolok pada saat Ejaan Van Ophuijsen dan ejaan yang saat ini digunakan.

Penulisan huruf $/ \mathrm{y} /$ ditulis huruf $/ \mathrm{j} /$, misalnya terdapat kata [sayang] ditulis dengan menggunakan kata [sajang]; terdapat pula kata [yakin] ditulis dengan menggunakan kata [jakin]. Dua kata tersebut hanya beberapa contoh kata yang digunakan pada Ejaan Van Ophuijsen yang belum pernah digunakan oleh mahasiswa pada era milenial ini, mereka hanya mengetahui melalui sejarah. 
Penulisan huruf /u/ ditulis huruf /oe/, sering kali kita menjumpai tulisan nama dari Presiden Indonesia yang pertama yaitu Ir. Soekarno, pada penulisan nama tersebut ditulis dengan [soekarno], tapi dalam pelafalannya adalah [sukarno]. Terdapat pula contoh penggunaan kata "umum”, pada Ejaan Van Ophuijsen ditulis [oemoem] dalam pelafalannya adalah [umum].

Setelah Ejaan Van Ophuijsen berganti menjadi Ejaan Republik atau yang biasa dikenal dengan Ejaan Soewandi, sejarah dari ejaan ini Prof. Ir. R. M. Soewandi Notokoesoemo adalah Menteri Pengajaran, Pendidikan, dan Kebudayaan Indonesia tahun 1955-1956 pada kabinet Burhanudin Harahap. Beliau lulus sebagai insinyur sipil dari Techniche Hoogeschool te Bandung (sekarang menjadi ITB) pada Desember 1936. untuk menyempurnakan \& menyederhanakan sistem Ejaan Van Ophuijsen, Soewandi menyusun ejaan baru yang bernama Ejaan Republik tahun 1947.

Ada beberapa perubahan pada Ejaan Republik dari ejaan yang sebelumnya, gabungan huruf /oe/ yang digunakan pada ejaan sebelumnya diubah penulisannya menjadi huruf /u/. Pada ejaan sebelumnya penulisan kata [pendoedoek] diubah menjadi [penduduk].

Setelah Ejaan Republik berganti nama lagi menjadi Ejaan Melindo, Kata Melindo merupakan akronim dari Melayau-Indonesia.
Ejaan ini disusun atas kerja sama antara pihak Indonesia Slamet Muljana dan pihak Persekutuan Tanah Melayu (Malaysia) oleh Syed Nasir bin Ismail yang tergabung dalam panitia kerja sama Bahasa Melayu-Indonesia pada tahun 1959 .

Hal yang berbeda dari Ejaan Melindo dari dua ejaan yang sebelumnya yaitu adanya perubahan penulisan gabungan huruf /tj/ diganti menjadi huruf /c/. penulisan kata [tjinta], pada Ejaan Melindo yakni [cinta].

Pada ejaan kali ini, mahasiswa sudah melewatinya. Ketika di jenjang pendidikan SD, SMP, SMA telah mempelajari Ejaan yang Disempurnakan (EyD). Pada ejaan ini, semua mahasiswa dalam anggota zoom meeting telah mempelajari ejaan ini, pada jenjang SD, SMP, dan SMA.

Sejarah dari Ejaan yang Disempurnakan (EyD) diresmikan oleh Presiden RI Soeharto pada 17 Agustus 1972. ejaan ini diresmikan atas dasar putusan Presiden No. 57 tahun 1972 dengan nama Ejaan yang Disempurnakan (EyD) yang berupa pemaparan kaidah ejaan yang lebih luas dan penggunaannya diresmikan dengan Surat Putusan Menteri Pendidikan dan Kebudayaan tanggal 27 Agustus 1975 No 0196/U/1975.

Pada ejaan ini, huruf /q/ dan /x/ yang lazim digunakan dalam bidang ilmu pengetahuan tetap digunakan. Misalnya [quadrant], [xenom], [xiliografi] dan 
sebagainya. Salah satu yang sering salah digunakan oleh pelajar secara umum dan mahasiswa secara khususnya pada pembinaan melalui zoom meeting ini yakni penggunaan kata depan "di" dan imbuhan "-di". Penulisan kata depan "di" penulisannya harus dipisah dengan kata berikutnya, sebaliknya penggunaan kata imbuhan "-di" penulisan harus digabungkan dengan kata berikutnya, contoh kata depan "di" yaitu [di rumah], contoh penulisan imbuhan "-di" yaitu [dibaca].

Ejaan yang terbaru mulai muncul pada 26 November 2015 oleh Menteri Pendidikan dan Kebudayaan pada saat itu yaitu H. Anies Rasyid Baswedan, S.E., M.P.P., Ph.D., dan resmi digunakan pada 30 November 2015 oleh Direktur Jenderal Perundang-undangan Kemenkumham. Pedoman ini merupakan edisi keempat berdasarkan peraturan Kemendikbud No. 50 tahun 2015, Ejaan ini diberi nama Pedoman Umum Ejaan Bahasa Indonesia (PUEBI).

Perubahan ejaan ini bukan berarti mengubah secara keseluruhan isi dari EyD, terdapat beberapa yang diubah dari EyD ke PUEBI, yaitu penambahan huruf diftong /ei/. Pada EyD hanya ada tiga huruf diftong yaitu /ai/ contoh kata [pandai], diftong /au/ contoh kata [autodidak], diftong /oi/ contoh kata [boikot] dan penambahan diftong pada PUEBI /ei/ contoh kata [survei].
Pada ejaan ini, peserta zoom meeting belum mengenal bahkan terasa asing ditelinga mereka ketika mendengar PUEBI. Sebenarnya ejaan ini, sudah mereka kenal ketika duduk dibangku SMA, tetapi ketika itu mereka masih menggunakan EyD. Sekolah belum mengenalkan PUEBI kepada siswa, tapi salah satu materi pada contoh PUEBI di atas telah mereka dapatkan ketika di sekolah.

\section{Pembinaan Bahasa Indonesia melalui} Media Sosial

Media sosial sangat menjamur disemua kalangan, termasuk mahasiswa hampir semua memiliki akun media sosial baik itu intagram, tik tok, facebook, dan lain sebagainya. Pada masa pandemi Covid-19 ini, peran media sosial sangat membantu dalam pelaksanaan pembinaan bahasa Indonesia karena jangkauan yang sangat luas dan tidak harus tatap muka. Materi yang disajikan pada media sosial dikemas semenarik mungkin agar dapat diterima oleh kalangan milenial.

Media sosial yang digunakan pada pembinaan ini yaitu berfokus pada instagram dan tik tok. Pada media sosial instagram konten yang dibagikan berupa pembinaan bahasa Indonesia berfokus flyer kata baku dan padanan kata. Secara umum pembinaan bahasa Indonesia melalui media sosial dapat mencakup seluruh lapisan masyarakat dan khsusnya peserta pembinaan bahasa Indonesia yaitu lapisan mahasiswa seIndramayu. 

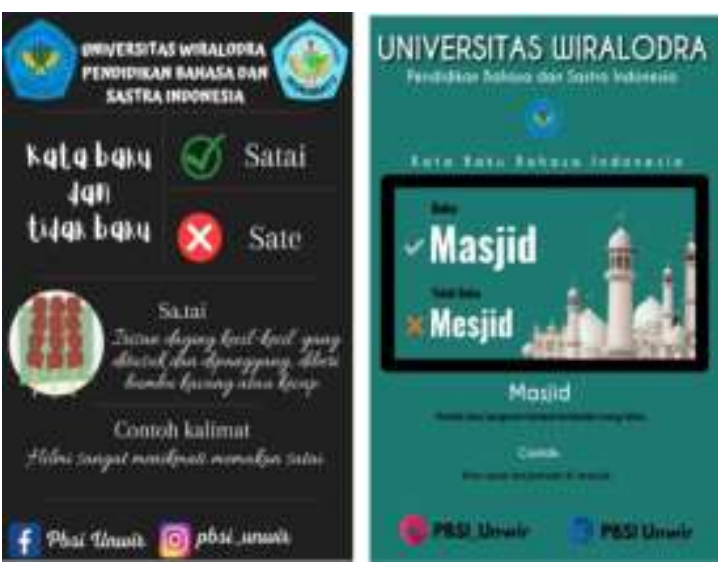

Setiap harinya konten kata baku diunggah pada media instagram Ebasi (Edukasi Bahasa Indonesia). Kata yang menjadi konten tersebut dalam pembinaan tersebut menggunakan kata yang sering dijumpai atau digunakan dalam kehidupan sehari-hari. Salah satu contoh kata baku tersebut yaitu penggunaan kata tidak baku [sate] menurut KBBI kata tidak baku dari [satai] yaitu irisan daging kecil yang ditusuk dan dipanggang, diberi bumbu kacang atau kecap. Kata yang sering digunakan oleh masyarakat luas yaitu [masjid] merupakan bentuk tidak baku dari [masjid] yaitu rumah atau bangunan tempat beribadah orang islam.

Selain kata baku yang diunggah pada media sosial instagram, fokus konten ini adalah padanan kata salah satu tujuan memberikan wawasan kepada masyarakat akan salah satu perkembangan bahasa Indonesia. Dengan konten padanan kata bertujuan agar masyarakat penutur bahasa Indonesia lebih sering menggunakan bahasa Indonesia daripada bahasa asing. Salah satu konten padanan kaya yang diunggah pada akun instagram yaitu

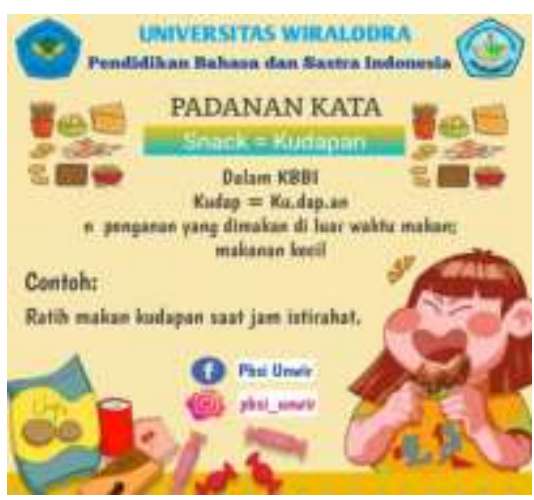

Pada padanan kata ini diambil contoh penggunaan kata [snack] dalam kamus bahasa Inggris memiliki arti “camilan”. Kata tersebut seringkali digunakan oleh masyarakat penutur bahasa ketika mengadakan sebuah acara perkumpulan atau rapat baik itu dari instansi pemerintahan atau di luar pemerintahan. Dalam kegiatan mahasiswa di luar Prodi Pendidikan Bahasa dan Sastra Indonesia hampir menggunakan kata [snack], padahal kata tersebut dalam bahasa Indonesia memiliki padanannya yakni [kudapan] dalam KBBI penganan yang dimakan di luar waktu makan; makanan kecil.

Selain media sosial instagram, pembinaan ini menggunakan media sosial tiktok. Konten yang digunakan tidak jauh berbeda dengan yang disuguhkan pada media intsgram yang membedakan hanya penyajiannya. Pada media instagram membuat konten tentang bahasa baku dan padanan kata dalam bentuk gambar, sedangkan pada media tik tok konten yang dibuat tentang bahasa baku dan padanan kata 
dalam bentuk sebuah video berdurasi \pm 1 menit.

Dari hasil pembinaan yang dilakukan melalui media sosial instagram dan tik tok, mendapatkan respons positif dari peserta pembinaan bahasa Indonesia. Banyak pengetahuan baru yang mereka dapatkan dari hasil unggahan. Hasil unggahan baik itu melalui instagram dan tik tok dapat menjadi bekal untuk semua kalangan dalam menggunakan bahasa Indonesia yang baik dan benar sesuai dengan PUEBI yang berlaku.

\section{SIMPULAN}

Menanamkan

pemahaman

penggunaan bahasa Indonesia yang baik dan benar dengan cara memberikan sedikit materi tentang sejarah perkembangan bahasa Indonesia kepada mahasiswa yang menjadi sampel dalam penelitian ini. Melalui unggahan konten dari instagram dan tik tok dapat memberikan bekal kepada mahasiswa dalam menggunakan bahasa Indonesia yang baik dan benar sesuai dengan kaidah kebahasaan yang sesuai dengan PUEBI baik secara lisan dan tulis.

\section{DAFTAR PUSTAKA}

Alwi, Hasan dkk. (2003). "Tata Bahasa Baku Indonesia”. Jakarta: Balai Pustaka.

Istiqomah, D. S., \& Istiqomah, D. S. (2018). "Analisis Penggunaan Bahasa Prokem dalam Media Sosial". Parole (Jurnal Pendidikan Bahasa dan Sastra Indonesia), 1(5), 665-674.
Laelasari, L., Oktavia, L., \& Mustika, I (2018). "Pengaruh bahasa alay terhadap penggunaan bahasa indonesia di kalangan mahasiswa ikip siliwangi". Parole (Jurnal Pendidikan Bahasa dan Sastra Indonesia), 1(5), 675-680.

Sahril. (2016). "Pemertahanan Bahasa Ibu Melalui Grup Whatsapp". Ranah: Jurnal Penelitian Sastra Vol. 5 No. 1, Juni 2016.

Soulisa, I. (2018). Penggunaan Bahasa Indonesia Lisan Baik dan Benar dalam Kelompok Kecil Kalangan Mahasiswa Prodi Bahasa dan Sastra Indonesia Universitas Victory Sorong. KREDO: Jurnal Ilmiah Bahasa dan Sastra, 2(1), 8187.

Sudaryanto, S., Hermanto, H., \& Gustiani, E. I. (2019). Media sosial sebagai sarana pembinaan bahasa Indonesia di era digital. Kode: Jurnal Bahasa, 8(4).

Sugiarto, Eko. 2017. "KITAB PUEBIPedoman Umum Ejaan Bahasa Indonesia”. Yogyakarta: ANDI.

Sugiyono. (2016). "Metode Penelitian Pendidikan (Kuantitatif, Kualitatif, dan R\&D)". Bandung: Alfabeta. 